\title{
An Efficient Wavelet based Automation Process for E-Admission in Universities of Odisha
}

\author{
Ghanashyam Rout \\ KIIT University \\ Bhubaneswar \\ Odisha,India
}

\author{
Sreedhar Madichetty \\ KIIT University \\ Bhubaneswar \\ Odisha,India
}

\author{
Sambeet Mishra \\ KIIT University \\ Bhubaneswar \\ Odisha,India
}

\author{
Srikanta Pattnaik \\ SOA University \\ Bhubaneswar \\ Odisha,India
}

\begin{abstract}
E-admission or electronic admission is an electronic mechanism which convert the traditional office paper processes into electronic processes. In this type of admission, It creates a paperless system which is done in web based network. This is an Internet Communication Tool, which would improve the performance in admission in Universities of Odisha. E-admission can encompass both intra-office and inter-office communication for any Universities of Odisha. The main objective is to introduce total transparency and accountability leading to better E-Governance with in any Universities of Odisha. This type initiative is especially targeted at any Universities of India or world where public accountability is of special concern. Similar processes are being developed in many universities to aid compliance with the educational act. This paper introduces a noble solution for E-admission through an efficient automatic software technique. The solution is more customer centric rather than organization centric. It is also independent of any specific individual and hence confirms the ethics of transparency. The process of E-admission is implemented by a distributive cooperative algorithm \& PSO based algorithm for fast searching. The data protection is achieved through wavelet techniques.
\end{abstract}

\section{Keywords}

E-admission, wavelet, automation, PSO, distributed system

\section{INTRODUCTION}

University is a system which can build a nation, educate and guide the teeming millions of the young generation in a systematic constructive and innovative way. E-admission is a system which generate inculcate a spirit of confidence, selfrespect and give them a deep insight into the State-of-the-Art, a far sighted wisdom and understanding and excellent education to the student throughout the world. So that admission of individual applicants is nevertheless at the discretion of the University having regard to the safety and welfare of the University community. The University will not admit the applicants unless there is a reasonable expectation that the applicant can fulfill the learning outcomes of the course and reach the required standard for the award. A university education has become a basic part of most people's preparation for working life. Admission to university is therefore a topic of importance. How a student chooses a university, and conversely how a university chooses a student, determines the success of both sides in carrying through the education. However, most existing studies of university admission [1-3] are based on the perspective of universities who are to receive the new incoming students, and not on the perspective of secondary schools that are sending their students to pursue higher education, or on the perspective of the student who has to decide which university to apply to. Given that the university knows very little about the applicant, whereas the secondary school knows a great deal more, there is value in extending the university admission process to include secondary schools. This paper proposes a novel design of a recommender system that can provide recommendations about which universities a student should apply to, taking not only the student's secondary school scores but also other factors into account. By combining both a decision tree approach and a neural network approach, an improved recommendation output can be achieved. The early admission programs are an essential part of the admission process at selective universities in Odisha. Recent empirical findings show that early admission standards are lower than regular admission standards. This gives rise to concerns about inefficiency in the selection of students that might be caused by early admission programs. The procedures for the admission of students are non-discriminatory and espouse the University's commitment to equal opportunities. Responsibility for the selection of student's lies with Admissions Tutors nominated by Heads of Department operating within the general entry requirements for the award specified by the University and any specific course based requirements. The selection of students is based on ability to benefit as demonstrated through prior educational achievement, motivation and commitment. This paper deals with the university admission process, focusing on how universities and students pursue their goals and how efficient the resulting outcome is. This paper shows that the early admission program may arise as an equilibrium phenomenon, and different admission standards result from an individual university's optimal choice to improve the selection of students. If universities have imperfect and independent observations of students' qualities, an adverse selection problem arises in the admission process, and then the students are dissatisfied. Among the admitted students in one university, the better quality students are more likely to be admitted by other universities and less likely to matriculate at this university. This results in a lower average quality of matriculating students than of admitted students. The early admission program will screen the students who will surely matriculate and enable a university to treat them differently. This paper also shows that the overall selection of students may improve with different admission standards in contrast to what is commonly believed. This is an ICT tool, which improve the productivity and performance in admission in Universities of Odisha. E-admission can encompass both intra-office and inter-office communication for any Universities of Odisha. The main objective is to introduce total transparency and accountability leading to better EGovernance within any Universities of Odisha. This type initiative is especially targeted at any Universities of India or 
world where public accountability is of special concern. Similar processes are being developed in many universities to aid compliance with the educational act[4],[5]. This paper introduces a noble solution for E-admission through an efficient automatic software technique .The solution is more customer centric rather than organization centric. It is also independent of any specific individual and hence confirms the ethics of transparency. The process of E-admission is implemented by a distributive co-operative algorithm. The data protection is achieved through wavelet techniques.

\section{LITERATURE REVIEW}

Many researchers have given various solutions for Eadmission. Kathy Cross \& et. al [4] emphasized that the University should be a paperless process to improve efficiency, expand capacity and enhance customer service to give the better solution through electronic document management system with automated workflow. The Admissions Office was selected for the initial implementation of the new system, including document archive and retrieval functionality and automated workflow processing, with plans to extend it to meet similar needs of other university offices over time. Simon Fong \& et.al [5] has pointed out that to choose a suitable University for a candidate was too difficult decision. The candidates look for the reputation of the university, perceived difficulty of the degree program, distance from home, tuition fees, living costs, candidate's areas of academic strength and actual scores in qualifying examination. Similarly, the university has its own set of admission criteria, mainly based on academic standard of the student to be admitted, but possibly also including others, such as minority and gender representation, local vs. domestic vs. overseas student proportion, and others. Choosing the most suitable among the many thousands of candidates that apply to a university every year is not a trivial matter. In [6] the authors have pointed out that an early admission program and the resulting different admission standard were university's optimal choice to improve the selection of students. In [7], authors have mentioned an e-admission process based on web for the universities of Sweden. But how to deal with the late applicants, interface with teachers and other important issue has not been addressed. The authors in [8] have presented the impact of mouse (e-admission) over that of pen (manual admission). They have concluded that the e-admission is a process which is fast, most satisfying and transparent than its manual counterparts.

\section{ADMISSION PROCESS}

Universities of Odisha conduct admissions for different programs in every academic year. It is anxious by the students that if they will file the application earlier and get decision immediately from University. There will be one standard Common Application Form (CAF) for admission to any stream of any of the Colleges under the Universities and Universities of Odisha are selected in E-admission. It is also proposed to have one Common Prospectus (CP) for these purposes. Both the Common Application Form (CAF) \& the Common Prospectus (CP) will be available in web based networking in National/International level. It will also be available in PDF format in the Universities of Odisha website as www.univodisha.in for downloading. It is recommended that students can apply early in their senior year of education of academic. Application review begins automatically up to the desired seat is filled up. After the strength was filled, the data base cannot accept the any CAF from the candidates. When the students fill up their CAF, at that time they should given at least three choices of courses. If first choice of college and stream (courses) is filled, then it will move to second choice and so on. The information of 1 st selection will be available in the website www.univodisha.in and also will be sent it to the applicant via SMS if they have mentioned the mobile number in CAF. The intimation letter will be sent to the selected candidate by post. Toll free number 1800-3456-770 will be available in website to meet the queries of the applicant in the matter of E-admission with the authority of Universities of odisha. Students who demonstrate sufficient academic strength and a readiness to accept the challenges of college-level work following the junior year of academic may apply for admission to Universities of Odisha through the early admission option. Students admitted through Early Admission will receive an academic certificate after completing the freshman year of full-time study at any colleges of Odisha. To apply for Early Admission, students should follow the standard freshman application process. In addition, they must submit letters from their parents and guidance counselor supporting their candidacy, and a reference from the teacher of an academic subject with whom they have studied indicating their readiness for college study. A personal interview on campus is strongly encouraged for them. Students who wish to take time off before enrolling in college may elect to have their admission deferred for a semester or a year by submitting a written request to the director of admissions. A non-refundable tuition deposit (\$200) will be required to hold a place in the subsequent entering class. Transfer students follow the same basic application process as freshman applicants. However, transfer applicants who have completed some years/semesters of college study can be evaluated on the basis of their college transcripts and need not required to submit relevant documents for records. Transfer credit is generally awarded for courses from regionally accredited institutions that are comparable to those offered at Universities of Odisha provided the student has earned a grade of certificate or better. A transfer credit evaluation is completed by the registrar at the time the student is accepted for admission. Candidates for the bachelor degree must satisfactorily complete a minimum of 30 credits of study at Universities of Odisha. A maximum of $90-$ 98 credits may be transferred from four-year institutions, and 60 - 64 from two-year institutions, depending on one's academic major. Applicants to certificate programs may transfer up to 15 credit hours. Transfer students who matriculate with 60 or more credits need to declare a major upon entering Universities of Odisha. Transfer students matriculating with an associate's degree or 57 credits from a four-year institution will be exempt from Components One and Two of Core. Transfer students matriculating without an associate's degree or 57 credits from a four-year institution who have completed basic skill requirements in writing, math, speech, or foreign language at another institution are exempt from corresponding requirements in Component One of Core. Component Three, Writing-intensive Courses, must be completed as described for transfer students in this catalog and in the Universities of Odisha regulation manual. E-admission aims to use Information Technology to process common applications for admission which would reduce time $\&$ improve efficiency for the college functionaries who have been doing it manually. It would also make the admission process economical, efficient, hassle free \& transparent for the students and their parents. The students/parents have to travel to only one of the number of colleges under E-admission process to be able to get admission to any stream of any college of their choices. International students enhance the cultural richness and diversity of a campus community. Universities of Odisha welcome to receive the applications 
from international students and seek to enroll those who have demonstrated academic potential in their home countries. Students whose native language is not English are required to submit proof of their proficiency in English. TOEFL (525/195), IELTS (6.0), and MELAB (77 - 81), and SAT scores will be accepted. International students will also be required to take additional English courses (ENG $100 / 101 / 102$ ) to prepare them for future writing-intensive courses and assignments at Universities of Odisha. International transfer students are welcome at Universities of Odisha and will receive credit for their past academic work from accredited international colleges and universities. Transcripts submitted for consideration of transfer credits must have an official translation into English.

\subsection{SELECTION CRITERIA}

Candidates will be selected primarily on the basis of academic selective honors programs, performance in honors courses performance and other curriculum achieve including outstanding performance in one or more academic subject areas, special projects, or programs; talents, achievements, experiences, or interests that will contribute to the vitality and educational environment of the campus; and special circumstances or personal challenges, especially as they relate to the social or educational environment(s), that have affected their life during in academic. The selection process for transfer candidates will require the rigorous academic preparation needed for admission to a major deserved course and follow the rule and regulation of Universities of Odisha. These seats are reserved for the Government service holder. Then the transfer students are advised to complete as much as possible of the required lower-division preparatory course work for their intended major prior to enrolling at Universities of Odisha. Then results of the selection process will be sent to the candidate their E-mail address or by post.

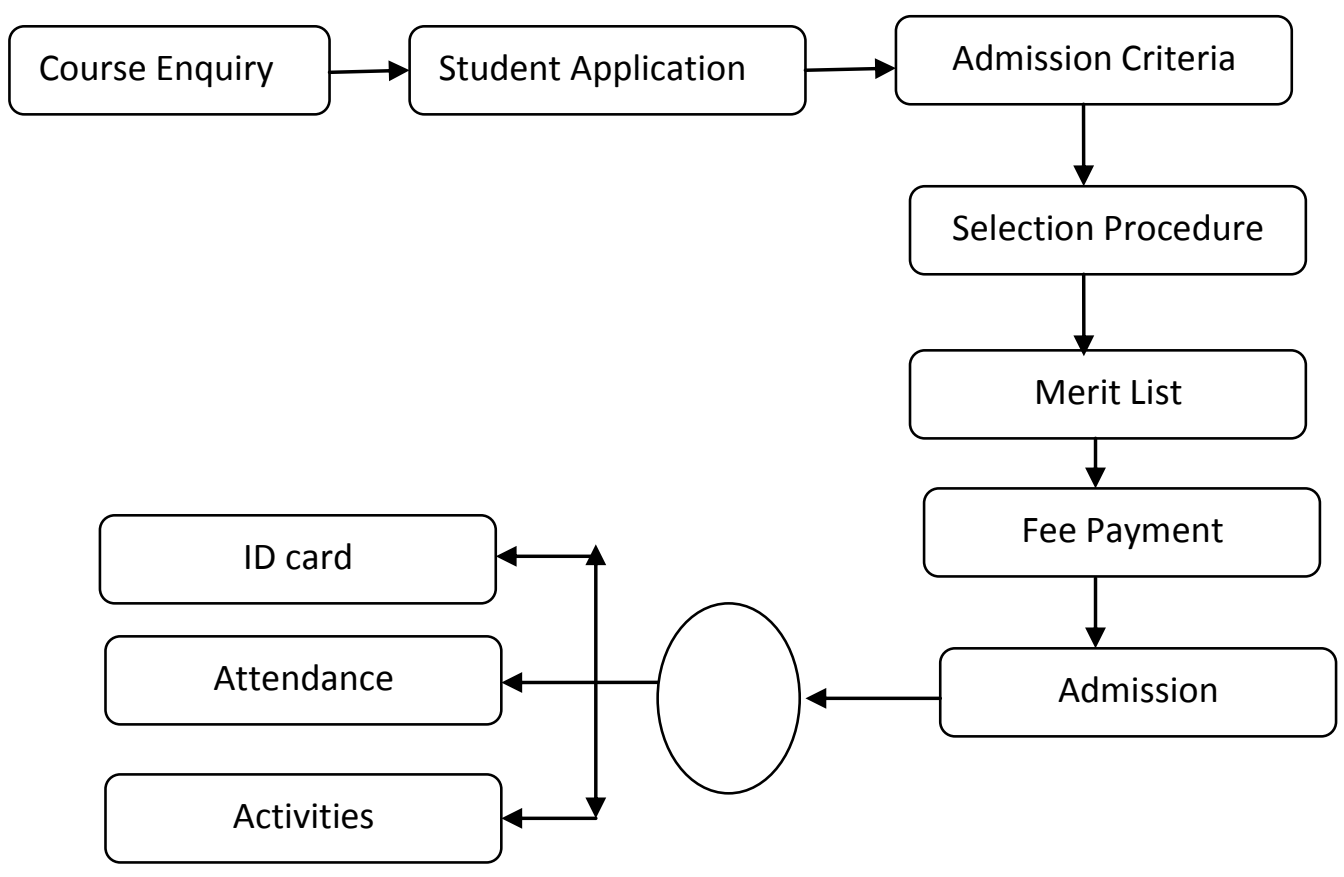

Fig.1: Criteria for Selection and Admission

\subsection{E-Admission Criteria}

Admission criteria of Universities of Odisha for fresh candidates are competitive, emphasizing the following primary academic factors :

The candidates have successful completion of curriculum (also known as college preparatory) in the final examination. The candidates have good performance in high school/secondary school as in class rank or grade point. The candidates have extracurricular activities had significant work experience or held leadership positions during in academic carrier. The competitive academic E-admissions software can review the process considering all these primary factors and selected the deserved candidates and displayed in displaying device as well as send the information to the desired candidates through E-mail which have given by the candidates earlier[9]. Overall authorities of Universities of Odisha have mentioned grade point average of at least 2.5 (on a 4.0 scale) as a cutoff grade point for E-admission.

\subsection{Rules and Regulation for E- Admission}

The authorities of Universities of Odisha have decided to adopt the following regulation for admission their courses. First the candidates access the Common Application Form (CAF) of Universities of Odisha website successfully and will carefully fill up it through the web. When the candidates will fill up of CAF, they should request to admit in desired courses in serially which is present on the CAF. Then the candidates submitted the CAF through the Universities web side of the Odisha and that will be entered in respective courses systematically in data base of Universities of Odisha. The admission application form must be submitted with desired documents which can be reasonably considered necessary. The common application form must be submitted to the desired website before dead line. Before dead line the efficient 
software of Universities of Odisha will take decision immediately. After dead line the efficient software of Universities of Odisha does not allow to enter the common application form to its data base. Then the efficient software of Universities of Odisha selected the candidates according to the cut off marks for different courses. Then the efficient software will take decision immediately and sent the information of selected candidates to the Universities notice board for displaying purposes and also sent the information to the selected candidates through the webs those who have mentioned their E-mail ID in the CAF. There is also mentioned the dead line of E-admission for different courses in Universities of Odisha website. The departmental Board will establish an admission committee for each program courses for fairness E-admission in Universities of Odisha. On behalf of the departmental Board will be issued with a proof of E-admission to the selected candidates by post for admitted in their desired courses in Universities of Odisha. The CAF will be not admitted in contravention of the admission rules. The desired documents which are required to fill up the CAF will be verified by the admission committee later on. If it is discovered that a candidate has been submitted on account of using unfair means then his/her admission will be cancel by committee members. Inter-program transfers will not be allowed at any stage of E-admission process. The information contained in the information brochure is only for general guidance and should not treat as legal document. The CAF of Universities Odisha can be change/modify time to time by the syndicate authorities. It is noted that ignorance of any rule cannot be treated as an excuse for its breach. All fees once paid are not refundable for any reason whatsoever. Only security deposited will be refunded after making necessary adjustments as required. The Universities of Odisha reserves its right to cancel the E-admission of successful candidate under any of the following circumstances. Such as:

i. If the fee is not deposited by the candidate in the stipulated date is given by authorities of Universities of Odisha.

ii. If the candidates do not joined the particular program by the stipulated minimum qualifications then their E-admission will be cancel by authorities of Universities of Odisha.

iii. No dispute will be raised after the expiry of twenty five days from the date on which the process of admission and/or selection has been completed.

iv. Whoever directly or indirectly commits, participates in, abets or propagates ragging inside or outside the campus may be punished which may extend to fine/ expulsion/rustication/ imprisonment.

All successful selected candidates will be bound by the above mentioned terms and conditions of Universities of Odisha. The students those who have read in previous year, but continuing in present year will also fill up their re-Eadmission CAF through Universities website. Then the authorities of Universities of Odisha will confirm about the candidates. The authorities of Universities of Odisha have followed the rules of state Government/Central Government to keeping some seats for the students of transfer of State Government/Central Government employees for different courses. The authorities of Universities of Odisha have obeyed the terms and conditions of state Government/ Central Government for reservation of schedule caste, schedule tribe, woman, physically handicapped, students of green card holder, students of defense person, and some seats for
International students to admit their Universities. The seats are reserved in following manner:

Schedule caste candidate- $7.5 \%$, Schedule tribe candidate$15 \%$, Woman candidate-33\%, Physically handicapped candidate-3\%, Defense candidate- $2 \%$, Green card candidate$2 \%$ and for International candidate-5\%.

If the number of students have some of score in different courses, then the Department Board of Universities of Odisha have right to conduct an E-examination to select the candidates for E-admission in respective courses. The CAF of Universities of Odisha has language column to fill up "ENGLISH" by the candidate. If students have filled other language instead of English, then their CAF will be rejected by the efficient software. The authorities of Universities of Odisha have decided to supply the visa to the students those who have admitted by embassy or consultant after depositing the desired currency. The committee of Universities of Odisha has decided the estimated fees for the academic year for different courses. They have right to increase the course fees time to time according to their budget. The Universities of Odisha have allowed health/technical programs in the under graduates/post graduates specific information which available in the Universities website. All types of information about health/technical program seen by students in the website of Universities of Odisha which will create curiosity mind to admit in it. All International students who have admitted in Universities of Odisha bounded to purchase the health insurance. International students must have completed the health insurance waiver form. The authorities of Universities of Odisha have decided to award the scholarship to the merit students and also awarded scholarship will renewable annually those who have got previously. The other reserve category students will the award scholarship as per the rule of state Government/ Central Government from Universities of Odisha. This type of program will encourage the students and makes satisfactory academic progress. The Universities of Odisha have provided the hostel facilities for boys and ladies candidates inside the campus. If the candidates will interest to stay in hostel then they will fill up the residence column in CAF. The annual fee structure for boarding and lodging will be mentioned in website of Universities of Odisha.

\subsection{Documentation for E-admission}

In Common Application Form (CAF) the National/International fresh candidates and previous year existing candidates can apply their applications through the Universities of Odisha web site. It is convenient and easy to apply through the website:

i. Apply Online. CAF may apply online using the Application for Undergraduate/Post Graduate PHD/any other programs Admission. The same application is used for freshman and transfer admission. The online application is secure and easy to use, and allows the students to save their work. Applying online also provides the students to get immediate notification whether their application has been received, and will likely speed up the processing of their application.

ii. Download a CAF. If the candidates prefer to apply on paper, they can download and print a copy of CAF of Universities of Odisha web site and send it to the same. The same application is used for fresh candidates and transfer admission candidates 


\section{EFFICIENT WEBLET BASED TECHNOLOGY FOR E-ADMISSION}

In E-admission solutions and services will be integrated into image technology process. In the long term, admission solutions and services are also likely to be integrated into electronic appliances, machines and information interfaces. Images are required for substantial storage and transmission resources. So advantage of image compression technique is required to reduce these data. This paper covers some back ground of wavelet analysis, data compression and how the wavelets have been used for image compression. The threshold is the extremely important influence of compression results to suggest the wavelet technique. As the image compression [9] is that much important one, for that purpose, we will consider an image and assume that the image in a matrix form. As we have to consider the image in matrix of pixel values. In order to compress the image, redundancies [10] must be exploited. For example such exploitations those areas where there is a little change or no change between the pixels are considered as same. Therefore the images having large area of uniform color will have large redundancies and conversely images that have frequent and large changes in color will be redundant and hard to compress. The analysis can be used to divide the information of image in to approximation and detail sub signals show the original trend of pixel values. Three detail sub signals show the vertical, horizontal and diagonal details or changing image. If these details are very small then they can be set to zero without significantly changes in the image. If these values are in the threshold, than they can set to zero [11]. Since those values are less that the threshold values then they will become to zero. In this way, if we get a lot of zeros, then we can say that the image is compressed extremely. After the image compression [12-13] is over that the aim is to get or retrieve the image. The process of retrieving decomposes the image from compression is called're-strained'. If the energy restrained is $100 \%$ that the process is called loss less energy re-strained and image is re-constructed exactly. If the image is not decompose totally, than the type of compression is called lose de-compression.

The important technical issues are discussed here.
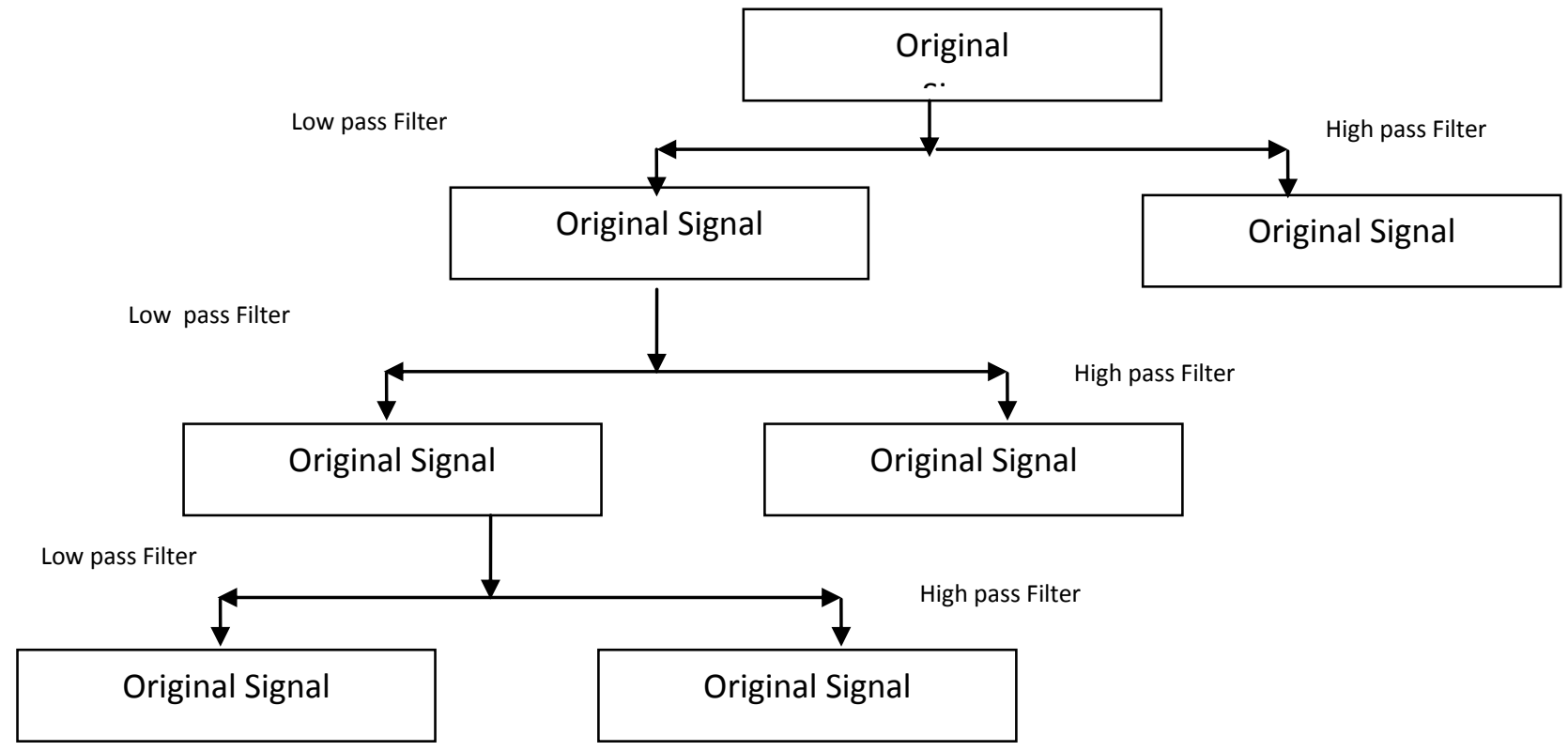

Fig.2(a)

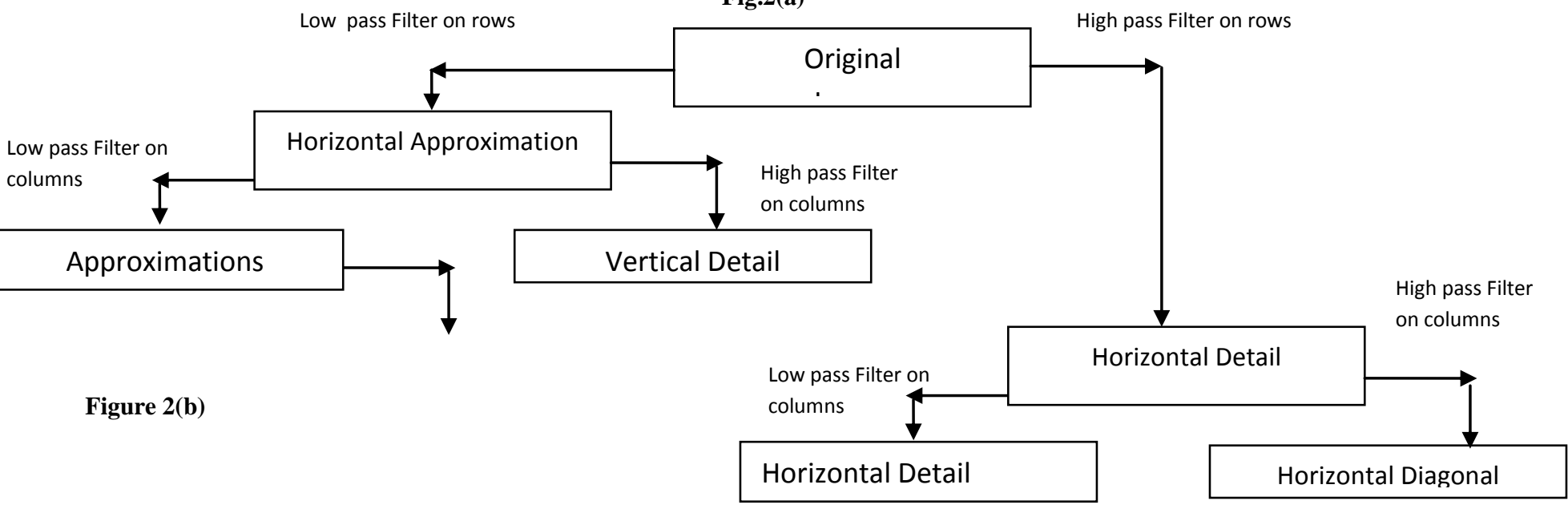

Fig.2 (a) \& (b) Working of Wavelet Technique by multi resolution analysis de-compressing and compressing respectively. 
After Compression, the decompression technique is used to retrieve the information with accuracy and that can be achieved by the intelligent mechanism techniques. Among lot of techniques are available we are going for the particle swarm optimization technique. In this technique we will follow an algorithm [14] for retrieval the exact information. According to that algorithm, it will follow and accurate information can be retrieved easily. There are a number of challenges associated with the long term preservation of digital data. In this paper, we are going to describe how the future desired data are preserved in digital document system. Of most interest to us for this paper are the requirements of future end users of a preserved digital data document. It is crucial when implementing an archival system for the long term preservation of digital data, to consider the end user's needs with respect to the preserved digital document. Such considerations aid in determining exactly what information should be preserved along with the digital document and in what way and we cannot predict everything at the end user. But it may to want to do with a preserved digital document in the future. Which we can assume that they will expect, at least to have the ability to view or interact with the data in the same way as today's users. As such, it is critical that preserved documents can be rendered authentically on future computers. Moreover, the digital document should be interpretable and understandable to future end users as well as remaining usable. As more research, educational and cultural institutions come to realize the enormity and complexity of work required to store, preserve, and accurate large amounts of their unique digital information. More over many will turn to establishing cooperative partnerships for leveraging existing mass-storage capacity or utilizing 3rd party data duration service providers to help satisfy their needs for a redundant and secure digital preservation system.

\subsection{Searching of the Exact Data}

For searching the desired data we have lot of algorithms, but among them they are not showing the exact data whatever we are required. For this purpose in this paper we are proposed a technique to search the data accurately with minimum time with without losing of information. That algorithm is the particle swarm optimization technique. By using this we can change the data from real format to binary format and it will search the desired information. Then it will show us the exact data within less time without losing the information. PSO is a population-based optimization technique developed by Kennedy and Eberhart (1995) and Shi and Eberhart (1998)
[15]. It is initialized with a population of random solutions. The algorithm searches for optima satisfying some performance index over generation. It uses the number of agents that constitutes a swarm moving around in the search space looking for best solution. The PSO technique can generate high quality of optimization solution within a short computation time and exhibits a more stable convergence characteristic than other optimization methods. The PSO contains' individual swarms called 'particles'. Each particle represents a possible solution to a problem with $d$-dimensions and its genotype consists $2 * d$ parameters. First $d$-parameters represent the 'particle positions' and next $d$-parameters represent velocity components. These parameters move with an adaptable velocity within the search space and retain its own memory with the best position it ever reached. The parameters get changed when moving from present iteration to the next iteration. At every iteration, the fitness function as a quality measure is calculated by using its position vector. Each particle keeps track of its own position, which is associated with the best fitness which has achieved so far. The best position obtained so far for particle $i$ keeps the track.

A large inertia weight (w) (Fig.3) facilitates a global search while a small inertia weight facilitates a local search. By linearly decreasing the inertia weight from a relatively large value to a small value through the course of the PSO run gives the best PSO performance compared with fixed inertia weight settings.

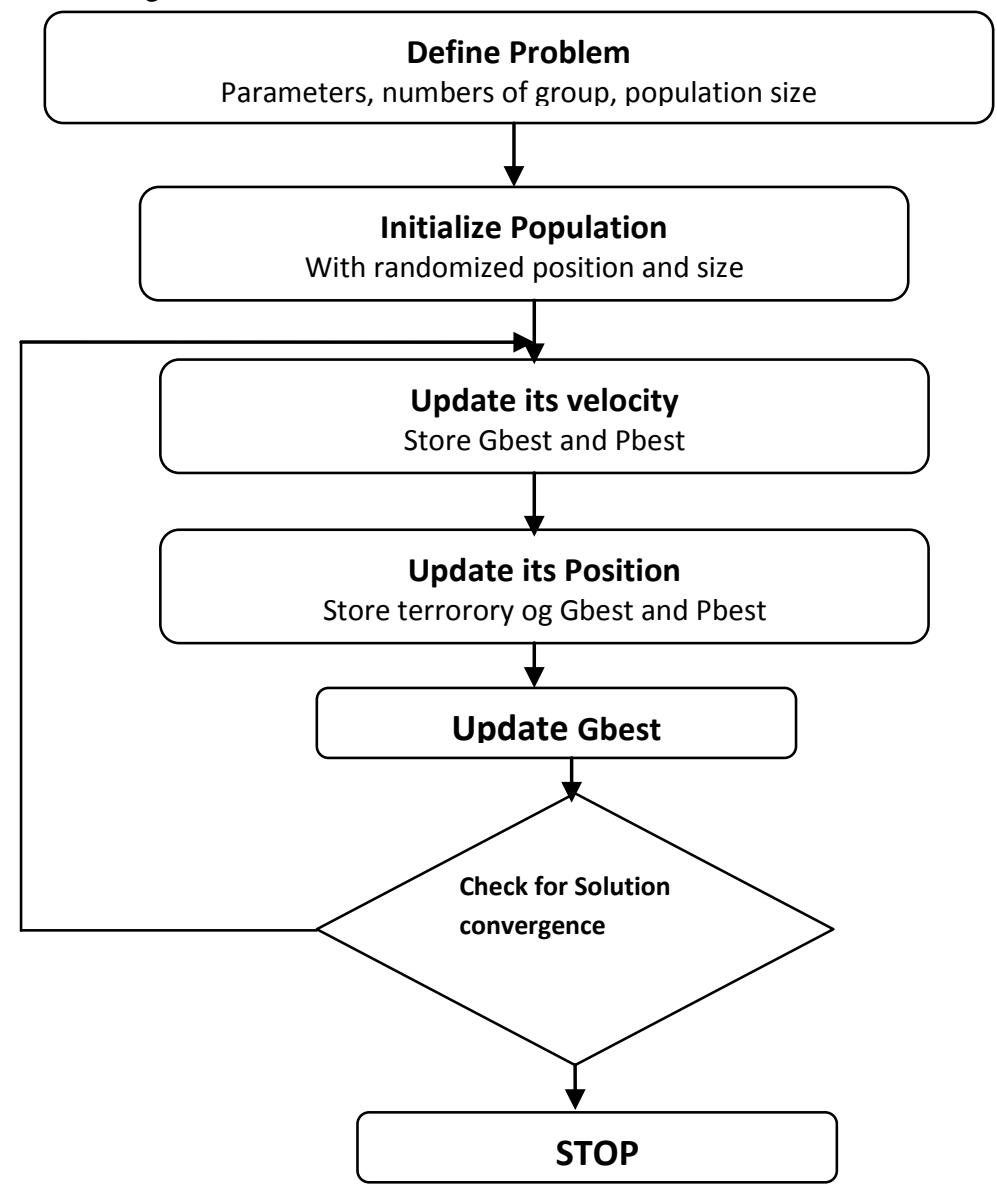

Fig.3.Inertia weight factor 


\subsection{Image Search Algorithm by Using Distributive Co-Operating Technique}

A distributed system is one in which the processors are less strongly connected. A typical distributed system consists of many independent computers in the same room, attached via network connections. Such an arrangement is often called a cluster [16-17]. A distributed algorithm is an algorithm designed to run on computer Hardware constructed from interconnected processors. Distributed algorithms are used in many variety application areas of distributed computing, such as telecommunications, scientific computing, distributed information processing and real-time process control [18-19]. Standard problems solved by distributed algorithm are included leader election, consensus, and distributed search, spanning tree generation, mutual exclusion \& resource allocation. Distributed algorithms are typically executed concurrently with separate parts of the algorithm being run simultaneously on independent processors $\&$ having limited information about what the other parts of the algorithm are doing. One of the major challenges in developing and implementing distributed algorithm is successfully coordinating the independent part of the algorithm in the face of processor failure and unreliable communications links. The choice of appropriate distributed algorithm to solve a problem depends both on the characteristics of the problem and the system. The algorithm will run in such a manner that the probability or link wills not failure. The kind of inter-process communication can be performed with help of the level of timing synchronization between separate processors. The distributed object-oriented paradigm helps the designer to master the complexity of cooperative systems. To specify a

system easily. The configuration of a distributed algorithm is composed from the states as its processes and the messages in its channels. A transition is associated to an event at one of its processes. A process can perform internal, send and receive events. So a process is an internal or send event. An algorithm is centralized if there is exactly one initiator. A decentralized algorithm can have multiple initiators. To search any picture we have to use the Thumbnail of the Image as a query, because Thumbnail of any Images are parts of the picture regardless whatever the background. By using one universal Image search algorithm that can capable to represent the features of any multimedia data type for solving the problems. We will use the contents of the Picture as our index key which uses a K-Tree [20]. A directed graph, containing $2^{\mathrm{k}}$ incoming nodes and one outgoing node have some benefits for the degree of $\mathrm{K}$ is affected by the complexity of the datastructure. For another data type we will reuse an algorithms particular feature. Secondly the Information's stored at the higher level of the tree are the lower amount of the feature to describe the global Information. On the other hand the higher Information and the features are stored at the lower level of the tree. Therefore the user's requirements can be adapted between the time and the accuracy by selecting appropriate level of the tree. Thirdly the features of K-Tree are independent, so the position of the nodes in the tree is same. The problem of inconsistent index structure occurs when a multiple-feature query comes. If the indices of different structures or different data types are processed individually, the database join operation is needed to merge results from each individual index and filters that do not comply with the temporal or spatial constraints. By using the K-Tree to search every feature altogether takes shorter computing time than using feature-dependent structure to search onmany indices individually, then merge all results and filters them with spatial constraints. distributed algorithm, we observe it from three points of view: the group of objects (a set of distributed entities involved in a distributed computation), objects (a local entity), and their methods (an action that can be performed). In our methodology we define an abstract machine specification as an equivalent state/transition model. A state is mainly characterized by its assertion definition. Such an assertion is first expressed using classical logic operators applied to methods on remote or local objects. We add other logic operators to include parallel and distributed features. They allow expressing knowledge and belief predicates. For the final implementation step these operators are realized by particular method calls. Finally a state predicate is verified if it takes a value in a defined set of possible values. A transition is associated with an action to be performed. In fact we use condition/action systems. An enabling condition for a transition is checked and, only if it is true, the corresponding action is executed. Refinement transforms step by step an abstract model (in the remaining of the paper we use invariably the terms specification and model) of a software system into an executable code. It must be emphasized that, by our different refinement steps, each model inherits the behavioral and knowledge aspects from higher levels. For instance, when a knowledge predicate is used in a group specification, the corresponding knowledge predicate will be found in the object specification level (for instance by the way of Boolean local variables). A distributed system is an interconnected collection of Autonomous process. Such as: Information exchange (WAN), resource sharing (LAN), Multicourse programming, Parallelization to increase performance etc. Replication is increase reliability and, modularity is improved to design the

\subsection{The Generalized Retrieval Model}

The $k$-tree structure is used to retain location information and also a histogram is used to store the characteristics of each portion of the data that corresponds to a part of the tree. This generalized model is depicted in Figure 4.First, either general mathematical models, or special methods, extract the feature of interest. Second, the domain of data type is reduced into a set and each item in the database is also mapped to the set. Third, virtual data values are added to data items, if necessary, to create such that each item will generate a balanced $k$-tree. A $k$-tree is built using histogram values for each feature.

\subsubsection{Binary PSO based Searching Algorithm}

Binary PSO based multi-objective Rule Selection Algorithm to perform multi-objective rule selection; we have already extracted $\mathrm{N}$ classification rules in the rule discovery phase of classification rule mining. These $\mathrm{N}$ rules are used as candidate rules in the rule selection phase.

Let $\mathrm{S}$ be a subset of the $\mathrm{N}$ candidate rules (i.e. $\mathrm{S}$ is a classifier). A binary string of length $\mathrm{N}$ represent $\mathrm{S}$, where " 1 " means the inclusion in $\mathrm{S}$ and "0" means the exclusion from $\mathrm{S}$ of the corresponding candidate rule. We use binary MOPSO to search for pare to optimal rule sets of the following threeobjective rule selection problem.

\section{Maximize fl( $(S)$}

Where $\mathrm{f1}(\mathrm{S})$ is the number of correctly Classified training patterns by $\mathrm{S}$,

Minimize $f 2(S)$

Where $\mathrm{f} 2(\mathrm{~S})$ is the number of selected rules in $\mathrm{S}$,

Minimize f3(S) 


\section{Maximize $f 1(S)$}

Where $\mathrm{f} 1(\mathrm{~S})$ is the number of correctly Classified training patterns by $S$,

\section{Minimize $f 2(S)$}

Where $\mathrm{f} 2(\mathrm{~S})$ is the number of selected rules in $\mathrm{S}$,

\section{Minimize f3(S)}

Where $\mathrm{f} 3(\mathrm{~S})$ is the total number of antecedent condition over selected rules in The first objective is maximized while the second and third objectives are minimized.

The third objective can be viewed as the minimization of the total rule length since the number of antecedent condition of each rule is often reformed to as the rule length.

\section{Algorithm}

Step-1: Initialise the population POP:

Randomly generate Npop binary strings (particles) of length

$\mathrm{N}$ is (no.of candidate rules extracted in rule Extraction phase)

Step-2: Initialise the position of each particle:

For $\mathrm{i}=1$ to Npop, $\mathrm{xt}(\mathrm{i})=$ pop [i]

Step-3: Initialise the velocity of each particle:

For $i=1 \mu$ Npop, vt $[i]=0 /$ initializing each velocity with single of 0 's /

Step-4: Initialise the $\mathrm{P}$ best of each particle:

For $\mathrm{i}=1$ to Npop, PBEST[i]=xt[i]

Step-5: Evaluate the fitness of each particle $/ *$ compute $\mathrm{f1}(\mathrm{s})$, f2(s) \& f3(s)

Step-6: Store the position of the particles that represent nondominated vectors in the reposition REP. Step-7: WHILE maximum number of cycles has not been reached

(a) Compute the best for each particle in the reposition REP applying k-mediod clustering technique on two objective criterions coverage and confidence.

(b) Compute the speed of each particle using the following expression bit wise

(b) For $\mathrm{C}=1 \quad$ to $\quad \mathrm{L}$ $\mathrm{vt}+1[\mathrm{i}][1]=\mathrm{vt}$ [i] [1]+Rand( ) $($ PBRST [i] [1] -xt [i] [()] + Rand (0) (G BEST [i] [1]-xt [i] [()] /x Rand $($ ) tables the values in the range $(0.1)$

(c) Update the new positions of the particles $x t+1[i]$ bitwise: For $\quad l=1$ to L,Calculate the threshold value If (rand ()$<\mathrm{w})$ then $\mathrm{xt}+1 \quad[\mathrm{i}]-\quad[1]=1$ else $\quad x t+1,[i]-[1]=0$ (d) Evaluate the fitness of each of the new particles in pop (e) Update the p best of each particle

(f) Update the contents of reposition REP by inserting all the currently non-dominated particles into the reposition. Any dominated totaling from the reposition are eliminated in the process, since the size of the reposition is limited, wherever it gets full, a secondary criterions for refection known as crowding distance technique is applied. The final result of PSO-based multi objective rule selection (all the final nondominated particle in the reporting) is not a single rule set but a number of non-dominated rule sets with respect to the three Tentative_Location1) objectives in (7). This is the main characteristic feature of PSO-based multi-objective rule selection.

\subsection{ALGORITHM: Virtual Node}

\section{The Virtual-Node (VN) in-picture search algorithm}

Case A) if query's tree aligns within the k-tree structure of data:

1. Find the distances between feature in root of the query tree and nodes of the data at level Li-1 - nodes with solid-line link - of the stored item. If distances are equal to the distance between the query and their parents, the query could be found within those child nodes.

2 Repeat

Case A) Recursively on this child node. If there is no distance at level $\mathrm{Li}-1$ close to the distance to the parent, the query is "not aligned". Follow Case B below.

Case B) if the query data falls in between two or more nodes:

1. If no node in $k$-tree can be a candidate, Virtual nodes (white nodes) between two nodes have to be generated from the parts of their child nodes.

2. Repeat the whole algorithm into a new tree; use the whole algorithm within the dashed box.

Case C) If height of query is equal to a node height:

1 Use histogram distance function to calculate the distance then

2 Return the distance and location

\subsubsection{Picture Search Algorithm: (Generalized Virtual Node)}

Extended_Query=Add_Dummies (Query)

Feature_Of_Extended_Query = Feature_Extraction

(Extended_Query)

VirtualNodeComparison (Feature_Of_Extended_Query,

Feature_Of_Extended_Data, ROOT, distance,

Tentative Location)

IF (distance < threshold) THEN BEGIN

Find "Query Representative," the largest node in the k-tree of feature_Of_Query, where no parts of dummies are included.

Virtual Node Comparison (Query Representative, Feature_Of_Extended_Data,

Tentative Location, distance1,

IF (distance1 < threshold1) THEN BEGIN

Find the final distance by calculating the distance between the query and area of data where the beginning of the area is at Tentative_Location 1 .

Distance $=$ distance

Location $=$ Tentative_Location 1

RETURN

END

END 


\section{CONCLUSION}

Imaging and automated workflow have enabled a major transformation of the E-admission process at Universities of Odisha. This paper has given a new solution to the Eadmission system. Most of the problems regarding admission in academic system have been addressed. The process is further optimized through Binary PSO based multi-objective Rule Selection Algorithm. All application material will be stored in imaged form, and admissions staff will use automated workflow to process applications electronically. The end results will be low cost, transparent and faster.

\section{REFERENCES}

[1] J. C. Garcia and A. I. Zanfrillo, Data Mining Application to Decision-Making Processes in University Management, INFOCOMP Journal of Computer Science, volume 6, no.1 pp.57-65, 2007.

[2] J. Luan, Data Mining Application in Higher Education, SPSS Executive Report, 2002.

[3] J. Luan, Data Mining as Driven by Knowledge Management in Higher Education-Persistence Clustering And Prediction, Keynote speech at the University of California-San Francisco's SPSS Public Roadshow, 2001.

[4] Kathy Cross, Lavon R. Frazier, Lynn Hulett "Streamlining the Admissions Process with Imaging and Workflow" Washington State University Pullman, Washington

[5] Simon Fong and Robert P. Biuk-Agha " An Automated University Admission Recommender System for Secondary School Students"

[6] Sam-Ho Lee* "Early Admission Program: Does It Hurt Efficiency? University of Pennsylvania Department of Economics 3718 Locust Walk Philadelphia, PA 19104 samho@ssc.upenn.edu Oct 2002

[7] Anders Mobjörk " A Unified Process for Admissions to Higher Education in Sweden" 1 The National Agency for Services to Universities and University Colleges (VHS), Box 24070, S-104 50 Stockholm, anders.mobjork@vhs.se

[8] Gifford, Denise, Briceo-Perriott, Juanita, Mianzo, Frank "Pen to Mouse: Web-Based Technology's Impact on College Admission Applications"
[9]. A. S. Lewis and G. Knowles, "Image compression using the 2-D wavelet transform," IEEE Trans. Image Processing, vol. 1, pp. 244-250, Apr. 1992.

[10] M. Antonini, M. Barland, P. Mathieu, and I. Daubechies, "Image coding using the wavelet transform," IEEE Trans. Image Processing, vol. 1, pp. 205-220, Apr. 1992.

[11] J.M.Shapiro,"Embedded image coding using zero trees of wavelet coefficients," IEEE Trans. Signal Processing, vol.41, pp.3445-3463, Dec.1993.

[12] M. L. Hilton, "Compressing still and moving images with wavelets," Multimedia Syst., vol. 2, no. 3, pp. 218-227, 1994.

[13]. Z. Xiang, K. Ramchandran, M. T. Orchard, and Y. Q. Zhang, "A comparative study of DCT- and waveletbased image coding," IEEE Trans. Circuits Syst. Video Technol., vol. 9, pp. 692-695, Apr. 1999

[14] E. Feig, "A fast scaled DCT algorithm," Proc. SPIEImage Process. Algorithms Techn., vol. 1244, pp. 2-13, Feb. 1990.

[15] Kennedy.J; Eberhart.R; "Particle Swarm Optimizing" Bur. Of Labor stat. Washington,DC,USA. IEEE, International Conference on Nov/Dec 1995.

[16] Grill-Specter, K., Sayres, R., and Ress, D. (2006). "Highresolution imaging reveals highly selective no face clusters in the uniform face area." Nature Neuroscience 9 (9) $1177-1185$

[17] Haxby, J., Gobbini, M., Furey, M., Ishai, A., Schouten, J., and Pietrini, P.(2001).” Distributed and Overlapping Representations of Faces and Objects in Ventral Temporal Cortex Science" 293 2425-2430

[18] LaConte, S., Peltier, S., and Hu, X. (2002). "Real-Time fMRI Using Brain-State Classification Human Brain Mapping "28 1033-1044

[19] S. Bauer, B. Zovko-Cihlar, and M. Grgic, "The influence of impairments from digital compression of video signal on perceived picture quality," in Proc. 3rd Int. Workshop Image and Signal Processing, IWISP'96, Manchester, U.K., 1996, pp. 245-248.

[20] A.Said and W.A.Pearlman, "A new fast and efficient image codec based on set partitioning in hierarchical trees", IEEE Trans. Circuit Syst. Video Technol., vol.6, pp.243-250, June 1996 